\title{
Population specificity of the DNAl1 gene mutation spectrum in primary ciliary dyskinesia (PCD)
}

\author{
Ewa Ziętkiewicz ${ }^{1 *}$, Barbara Nitka ${ }^{1 \dagger}$, Katarzyna Voelkel $^{1 \dagger}$, Urszula Skrzypczak1 $^{1}$ Zuzanna Bukowy ${ }^{1,3}$, Ewa Rutkiewicz ${ }^{1}$
} Kinga Humińska', Hanna Przystałowska', Andrzej Pogorzelski ${ }^{2}$, Michał Witt ${ }^{1,3}$

\begin{abstract}
Background: Mutations in the DNA/1 gene, encoding a component of outer dynein arms of the ciliary apparatus, are the second most important genetic cause of primary ciliary dyskinesia (PCD), the genetically heterogeneous recessive disorder with the prevalence of $\sim 1 / 20,000$. The estimates of the DNA/1 involvement in PCD pathogenesis differ among the reported studies, ranging from $4 \%$ to $10 \%$.

Methods: The coding sequence of DNA/1 was screened (SSCP analysis and direct sequencing) in a group of PCD patients (157 families, 185 affected individuals), the first ever studied large cohort of PCD patients of Slavic origin (mostly Polish); multiplex ligation-dependent probe amplification (MLPA) analysis was performed in a subset of $\sim 80$ families.

Results: Three previously reported mutations (IVS1+2-3insT, L513P and A538T) and two novel missense substitutions (C388Y and G515S) were identified in 12 families (i.e. 8\% of non-related Polish PCD patients). The structure of background SNP haplotypes indicated common origin of each of the two most frequent mutations, IVS1+2-3insT and A538T. MLPA analysis did not reveal any significant differences between patients and control samples. The Polish cohort was compared with all the previously studied PCD groups (a total of 487 families): IVS1 +2 -3insT remained the most prevalent pathogenetic change in DNAl1 (54\% of the mutations identified worldwide), and the increased global prevalence of A538T (14\%) was due to the contribution of the Polish cohort.

Conclusions: The worldwide involvement of DNA/1 mutations in PCD pathogenesis in families not preselected for ODA defects ranges from 7 to 10\%; this global estimate as well as the mutation profile differs in specific populations. Analysis of the background SNP haplotypes suggests that the increased frequency of chromosomes carrying A538T mutations in Polish patients may reflects local (Polish or Slavic) founder effect. Results of the MLPA analysis indicate that no large exonic deletions are involved in PCD pathogenesis.
\end{abstract}

\section{Background}

Primary ciliary dyskinesia (PCD; MIM \#242650) is a multisystem disease characterized by recurrent respiratory tract infections, sinusitis, bronchiectasis and male sub-fertility; in about half of patients it is associated with situs inversus (Kartagener syndrome, KS; MIM \#244400), resulting from the randomization of body symmetry (for the clarity we will refer to PCD families

\footnotetext{
* Correspondence: zietkiee@man.poznan.pl

+ Contributed equally

'Institute of Human Genetics, Poznań, Poland

Full list of author information is available at the end of the article
}

without s.i. as CDO, ciliary dyskinesia only). The complex PCD phenotype is caused by the impaired motility of respiratory cilia, embryonic node cilia and sperm tails, due to ultrastructural defects of these structures [1]. Transmission electron microscopy detects various structural aberrations of the axonemal ultrastructure in over $80 \%$ of the patients [2]. The most commonly reported defects involve absence or shortening of outer (ODA) or inner (IDA) dynein arms-molecular motor complexes composed of several heavy, intermediate and light dynein chains encoded by a number of genes dispersed throughout the genome.

\section{Biomed Central}


The prevalence of PCD is estimated at 1 in 20,000 live births $(1 / 12,500$ to $1 / 30,000)$, with the prevalence of $\mathrm{KS}$ being approximately two times lower [1]. PCD is usually inherited as an autosomal recessive trait, although pedigrees showing autosomal dominant or X-linked modes of inheritance have also been reported [3-6]. The complexity of the ciliary ultrastructure and the broad variety of cilia defects suggest genetic heterogeneity of the disease. Indeed, genetics of PCD is very complex, as witnessed by numerous linkage studies, which indicated several genomic regions potentially involved in PCD pathogenesis [e.g. [7-10]]; for the reviews see [11,12].

Among several genes confirmed to be directly involved in PCD pathogenesis, the major number of mutations were found in just two: DNAI1 (9p13.3) and DNAH5 (5p15.2), encoding intermediate and heavy chains of the axonemal dynein, respectively [13-21]. Mutations in other genes, coding for proteins involved in the axonemal ultrastructure (DNAH11, DNAI2, TXNDC3, RSPH9, RSPH4A) or assembly (KTU, CRRC50), were reported in singular PCD families only, and mutations in the RPGR gene were reported in rare cases of $\mathrm{PCD}$ associated with the X-linked retinitis pigmentosa (reviewed in [12]; see also [4,6,22-25]. Mutations in DNAI1 and DNAH5, both associated with the ODA defect phenotype, were collectively estimated to account for almost $40 \%(\sim 28 \%$ and $10 \%$ for DNAH5 and DNAI1, respectively) of PCD cases [2]. Recently, other authors [20] reported much lower involvement of DNAI1 (4\%). Here we report the results of DNAI1 screening performed in a large group of predominantly Polish PCD patients, the first large cohort of PCD patients of Slavic origin; the possibility that large, exonic deletions account for monoallelic mutations was also explored. Population specificity of DNAI1 mutation spectra is discussed in light of the SNP haplotype background of the mutations.

\section{Materials and methods}

\section{Patients}

A group of 157 PCD families included 185 affected individuals; parents and/or non-affected siblings were available in 115 families. Seventy-four of the families were classified as KS (if at least one affected member displayed s.i.); the remaining 83 were classified as CDO. At least one of the criteria listed in Table 1 had to be fulfilled to include a patient in the PCD cohort. All but six families (Czech/Slovakian) were of Polish origin. No known parental consanguinity was reported in the families (but such a possibility was not formally excluded).

\section{PCR amplification, SSCP/heteroduplex analysis and allele-} specific hybridization

Genomic DNA was isolated from peripheral blood lymphocytes using a standard salting-out extraction procedure. A specific primer pair was designed for each of the 20 DNAI1 exons, the 5' and 3' UTR regions, and for five intronic SNPs; the length of each amplicon was < $300 \mathrm{bp}$. For the SSCP analysis, PCR-amplified segments were denatured and separated in 7 or $8 \%$ polyacrylamide (29:1) in $0.5 x$ or $1 x T B E$; gels (optionally with $\sim 2 \mathrm{M}$ urea and $10 \%$ glycerol) were run at $8-10 \mathrm{~W}$ for $20-40 \mathrm{~h}$ at RT or $4^{\circ} \mathrm{C}$. Primer sequences, PCR conditions and detailed conditions used to separate each of the analyzed fragments are available from the authors upon request. The genotyping of SNPs and of newly found mutations was performed using dynamic ASO (allele-specific oligonucleotide) hybridization [26].

\section{Sequence analysis}

The nucleotide changes underlying all the detected SSCP migration variants were resolved by direct sequencing of the PCR products (BigDyeTerminator v3.1 on an ABI Prism 3130XL Analyzer, Applied Biosystems); trace files were checked and edited using FinchTV1.3.1. (Geospiza Inc.). Sequences were evaluated manually using Chromas 1.45 software and FASTA sequence comparison algorithm (http://fasta.bioch.virginia.edu/ fasta_www2). The reference genomic sequence was ENSG00000122735 (http://www.ensembl.org) or NG_008127.1 (http://www.ncbi.nlm.nih.gov); the exon boundaries were of the 699 aminoacid DNAI1-101 transcript ENST00000242317 (http://www.ensembl.org); the numbering of mutated nucleotide positions used throughout the text is that of cDNA.

\section{SNP-haplotype analysis and genetic stratification of the families}

Seven intragene SNPs (rs11547035, rs4879792, rs2274591, rs3793472, rs11793196, rs9657620, rs11999046) were genotyped and parental origin of the two alleles of each SNP was determined assuming, wherever possible, no recombination among the sites. The family-based information on SNP haplotypes was used to assess the haplotype variability in all the patients. The consistency of the disease cosegregation with the haplotype variants was examined in 79 families where DNAs from proband's siblings and parents were available.

\section{MLPA analysis of the DNAI1 gene}

A subset of PCD patients ( $~ 80$ families) were analyzed for the potential presence of large exonic mutation(s), using commercially available kit for multiplex ligationdependent probe amplification (MLPA) in the DNAI1 gene (P237-DNAI1; MRC Holland). The procedure was performed according to the manufacturer's indications (MRC Holland); briefly, hybridization of the multiple SALSA-MLPA probes (20 specific probe pairs targeting all DNAI1 exons) to total genomic DNA sample (50 ng per reaction) was performed at $60^{\circ} \mathrm{C}$, followed by 
Table 1 Clinical characteristic of the analyzed cohort

\begin{tabular}{ll}
\hline Criteria & Number of families \\
\hline Typical clinical manifestation of PCD* associated with s.i. & 74 KS \\
\hline Typical clinical symptoms without s.i., AND a defect in the ciliary ultrastructure in transmission electron microscopet & $32 \mathrm{CDO}^{\ddagger}$ \\
\hline Typical clinical symptoms without s.i. and the absence of ciliary motility as seen in the light microscope & 51 CD
\end{tabular}

*Recurrent upper respiratory tract infections, recurrent pneumonia, chronic bronchitis, bronchiectasis, sinusitis and otitis media, reduced mucociliary clearance as shown by a negative result of a saccharine test; ${ }^{\dagger}$ Usually lack of the outer/inner dynein arms, defective configuration of the microtubules; ${ }^{\ddagger}$ TEM data were also available for $35 \mathrm{KS}$ families. In nine families ( $5 \mathrm{CDO}$ and $4 \mathrm{KS}$ ), the diagnosis was supported by low values of nasal NO ( $<100$ parts per billion, ppb compared to normal $>600 \mathrm{ppb}[37,38])$.

ligation at $54^{\circ} \mathrm{C}$ and PCR with universal, FAM-labeled MLPA primers. The resulting amplicons were separated on ABI-Prism-3130XL Analyzer; peaks were analyzed using PeakScanner v1.0 software (Applied Biosystems).

\section{Results}

\section{Characteristics of the detected variants}

SSCP screening of the entire coding region of DNAI1 was performed in patients from 108 PCD families; systematic search for mutations was not executed in twenty-one families where the segregation of the SNP haplotype was inconsistent with that of the disease, as well as in twenty-eight families where mutations were identified in other PCD-related genes [EZ, unpublished data]. SSCP analysis revealed eight sequence variants. Two of them, in exon 1 and 11 (22G > T;A $8 \mathrm{~S}$ and 1003G > A;V335I, respectively), were frequent SNPs (rs11547035 and rs11793196), present at high frequencies in the general population. The remaining six SSCP variants represented three previously described PCD mutations and three changes never reported before (Figure 1). The $\mathrm{T}$ insertion at position +2 of intron 1 (IVS1+2-3insT), the most frequent mutation described until now in PCD patients, is known to affect a donor splice site [13]. It results in retaining $132 \mathrm{bp}$ of intron 1 in the mRNA and the premature termination of translation at amino acid position 25. In our study, the IVS1 +2 -3insT mutation was found on eleven independent chromosomes. It was homozygous in three families, accompanied by another mutation in three families and was the only mutation found in two families. Another previously reported mutation, the $1612 \mathrm{G}>\mathrm{A}$ in exon 17 resulting in a missense aminoacid incorporation A538T [18], was found on eight chromosomes; it was homozygous in three families, and in two others was accompanied by IVS1+2-3insT. The third of the previously reported mutations, the 1543G > A in exon 16 (G515S) [15], was found on one chromosome in a single patient. The second chromosome of that patient carried a 1538T > C transition in exon 16 (L513P); that change was never reported before. Another new mutation, the $1163 \mathrm{G}>$ A transition in exon 13 (C388Y), was found in a single patient (a compound heterozygote, with IVS1 +2 -3insT). The third new mutation, a G > A transition
245 bp downstream from the STOP codon, was found on one PCD chromosome; no change on the second chromosome was identified in the patient.

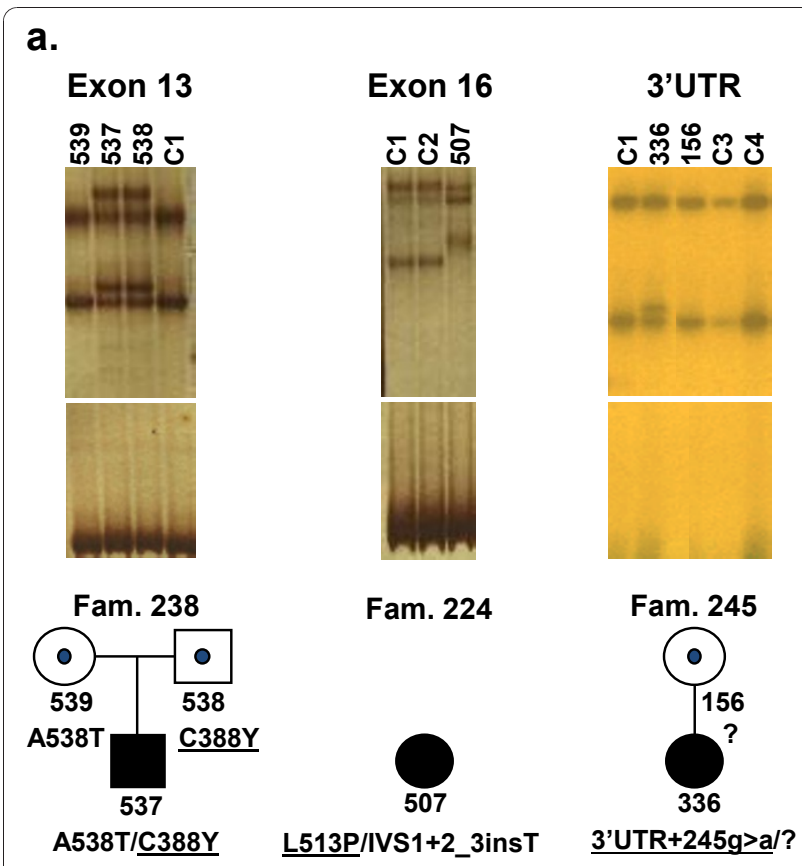

b.
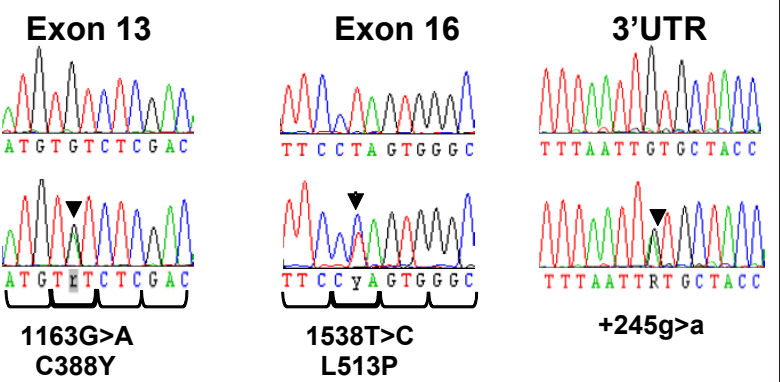

$+245 g>a$

Figure 1 Characteristics of three new variants detected in PCD patients. a. Results of the SSCP analysis revealing different migration patterns, and pedigrees of the families where new mutations/SNPs were identified. New mutations (in patients 537, in his father 538, and in patients 507 and 336) are underlined. "?" denotes unknown mutation; the carrier status is indicated by a dot in the pedigree symbols. b. Chromatograms of the new sequence variants. 
The data from the transmission electron microscopy were available for two PCD families with the homozygous mutation A538T/A538T and for two with compound mutations IVS1+2-3insT/A538T. In all these cases, the absence of ODA and/or IDA was noted; in three of the families the absence of dynein arms was accompanied by different, non-specific defects of microtubular organization (see Table 2). Phenotype penetrance in the families with homozygous or compound mutations was consistent with the recessive mode of PCD inheritance (family members who carried only one mutated chromosome did not exhibit any clinical symptoms); the pedigrees of the families harboring the newly described mutations are presented in Figure 1.

Sequence changes that resulted in a STOP or indel mutation, or affected the two most conserved donor or acceptor consensus splice site positions, were directly assumed to represent causative PCD mutations. In case of the new missense variants (L513P and C388Y), the possibility that the change represented a non-pathological polymorphism was dismissed following a number of analyses. Interrogation of the NCBI database for human single nucleotide polymorphisms (build 131; http://www.ncbi. nlm.nih.gov/SNP) indicated that no SNPs were reported at

Table 2 Details of patients' phenotypes and PCD-associated sequence changes detected in thirteen Polish families

\begin{tabular}{|c|c|c|c|c|c|c|c|c|c|c|c|c|}
\hline \multirow{2}{*}{$\begin{array}{l}\text { Family } \\
\quad \#\end{array}$} & \multirow{2}{*}{$\begin{array}{l}\text { Patient } \\
\quad \#\end{array}$} & \multirow[t]{2}{*}{ s.i. } & \multirow[t]{2}{*}{ nNO } & \multirow{2}{*}{$\begin{array}{l}\text { \% cilia with } \\
\text { the defects } \\
\text { identified } \\
\text { in electron } \\
\text { microscope }\end{array}$} & \multicolumn{4}{|c|}{ Mutation 1} & \multicolumn{4}{|c|}{ Mutation 2} \\
\hline & & & & & $\begin{array}{l}\text { Exon or } \\
\text { Intron }\end{array}$ & DNA & Protein & $\begin{array}{l}\text { SVM } \\
\text { score }\end{array}$ & $\begin{array}{l}\text { Exon or } \\
\text { Intron }\end{array}$ & DNA & Protein & $\begin{array}{l}\text { SVM } \\
\text { score }\end{array}$ \\
\hline 125 & 480 & yes & na & $\begin{array}{c}\text { 100\% ODA/IDA } \\
5 \% \mathrm{MT}\end{array}$ & 17 & $1612 G>A$ & A538T & -1.3 & 17 & $1612 \mathrm{G}>\mathrm{A}$ & A538T & -1.3 \\
\hline 106 & 412 & yes & na & $\begin{array}{c}\text { 38\%ODA/IDA } \\
46 \% \text { ODAorlDA } \\
23 \% \mathrm{MT}\end{array}$ & 17 & $1612 \mathrm{G}>\mathrm{A}$ & A538T & -1.3 & 17 & $1612 G>A$ & A538T & -1.3 \\
\hline$"$ & 413 & no & na & na & $"$ & $"$ & $"$ & $"$ & $"$ & $"$ & $"$ & $"$ \\
\hline 151 & 555 & yes & 47 & $\begin{array}{c}80 \% \text { ODA/IDA } \\
4 \% \text { MT }\end{array}$ & 17 & $1612 G>A$ & A538T & -1.3 & 17 & $1612 \mathrm{G}>\mathrm{A}$ & A538T & -1.3 \\
\hline$"$ & 556 & yes & 3 & $100 \%$ ODA/IDA & $"$ & $"$ & $"$ & $"$ & $"$ & $"$ & $"$ & $"$ \\
\hline 161 & 124 & yes & na & $\begin{array}{c}\text { 85\% ODA/IDA, } \\
9 \% \mathrm{MT}\end{array}$ & Intr1 & $\begin{array}{l}\text { IVS1+2- } \\
\text { 3insT }\end{array}$ & s17fsX25 & $\mathrm{nr}$ & 17 & $1612 G>A$ & A538T & -1.3 \\
\hline 108 & 421 & no & na & $\begin{array}{c}87 \% \text { ODA/IDA } \\
13 \% \text { IDA }\end{array}$ & Intr1 & $\begin{array}{l}\text { IVS1+2- } \\
\text { 3insT }\end{array}$ & $\mathrm{S} 17 \mathrm{fs} \times 25$ & $\mathrm{nr}$ & 17 & $1612 \mathrm{G}>\mathrm{A}$ & A538T & -1.3 \\
\hline$"$ & 422 & no & na & $\begin{array}{c}\text { 100\% ODA/IDA, } \\
\text { 13\% IDA, } 18 \% \\
\text { MT }\end{array}$ & $"$ & $"$ & $"$ & $"$ & $"$ & $"$ & $"$ & $"$ \\
\hline 124 & 478 & yes & na & na & Intr1 & $\begin{array}{l}\text { IVS1+2- } \\
\text { 3insT }\end{array}$ & $\mathrm{S} 17 \mathrm{fs} \times 25$ & $\mathrm{nr}$ & Intr1 & $\begin{array}{l}\text { IVS1+2- } \\
\text { 3insT }\end{array}$ & $\mathrm{S} 17 \mathrm{fs} \times 25$ & $\mathrm{nr}$ \\
\hline 112 & 434 & yes & na & na & Intr1 & $\begin{array}{l}\text { IVS1+2- } \\
\text { 3insT }\end{array}$ & $\mathrm{S} 17 \mathrm{fs} \times 25$ & $\mathrm{nr}$ & Intr1 & $\begin{array}{l}\text { IVS1+2- } \\
\text { 3insT }\end{array}$ & $S 17 f s \times 25$ & $\mathrm{nr}$ \\
\hline 231 & 520 & no & na & na & Intr1 & $\begin{array}{l}\text { IVS1+2- } \\
\text { 3insT }\end{array}$ & $\mathrm{s} 17 \mathrm{fs} \times 25$ & $\mathrm{nr}$ & Intr1 & $\begin{array}{l}\text { IVS1+2- } \\
\text { 3insT }\end{array}$ & $\mathrm{S} 17 \mathrm{fs} \times 25$ & $\mathrm{nr}$ \\
\hline 224 & 507 & yes & na & na & Intr1 & $\begin{array}{c}\text { IVS1+2- } \\
\text { 3insT }\end{array}$ & S17fsX25 & $\mathrm{nr}$ & 16 & $1538 \mathrm{~T}>\mathrm{C}$ & L513P & -2.1 \\
\hline 238 & 537 & yes & na & na & 13 & $1163 G>A$ & C388Y & -2.7 & 16 & $1543 G>A$ & G515S & -2.4 \\
\hline 244 & 548 & no & 48 & na & Intr1 & $\begin{array}{l}\text { IVS1+2- } \\
\text { 3insT }\end{array}$ & S17fsX25 & $\mathrm{nr}$ & $?$ & $?$ & $?$ & $?$ \\
\hline 216 & 355 & no & 37 & na & Intr1 & $\begin{array}{l}\text { IVS1+2- } \\
\text { 3insT }\end{array}$ & S17fsX25 & $\mathrm{nr}$ & $?$ & $?$ & $?$ & $?$ \\
\hline$"$ & 356 & no & 49 & na & $"$ & $"$ & $"$ & $"$ & $"$ & $"$ & $"$ & $"$ \\
\hline$"$ & 357 & no & 28 & na & $"$ & $"$ & $"$ & $"$ & $"$ & $"$ & $"$ & $"$ \\
\hline 145 & 336 & yes & na & na & 3'UTR & $+245 G>A$ & SNP & $\mathrm{nr}$ & $?$ & $?$ & $?$ & $?$ \\
\hline
\end{tabular}


the respective gene positions (1163G in exon 13, and $1538 \mathrm{~T}$ in exon 16). ASO screening of the control population ( 200 unrelated chromosomes from healthy Polish individuals) also did not reveal the mutated alleles. Comparison with the DNAI1 homologues from 9 Eutherian mammals, $P$. troglodytes, $P$. pygmaeus, G. gorilla, M. mulatta, M. musculus, $R$. norvegicus, B. taurus, C. famialiris, E. caballus (http://www.ensembl.org), indicated $100 \%$ conservation of DNA and aminoacid sequence at these two positions. This is consistent with the respective amino acids location within the DNAI1 protein: the $1163 \mathrm{G}$ > A substitution alters the C388 codon within the second of five highly conserved second WD-repeats (WD2) [13], and the $1538 \mathrm{~T}>\mathrm{C}$ in exon 16 changes the S513 codon in the highly conserved inter-repeat region, between WD3 and WD4 (Figure 2). The effect of the amino acid changes on the protein stability was examined using SNPs3 D online software http://www.snps3d.org; the SVM (Support Vector Machine) value smaller than -1.0 was assumed to indicate a deleterious effect of the amino acid substitution on the protein stability [27]. SVM scores obtained for C388Y and L513P were -2.74 and -2.17 , respectively; of note, negative SVM scores $(-2.50$ and -1.35) were also obtained for two previously reported missense mutations, G515 S and A538T. Based on all the above observations we tentatively assumed that the newly found missense changes in exons 13 and 16 represented the disease-causing mutations.

The causative role of the $+245 \mathrm{G}>\mathrm{A}$ transition in the 3'UTR region of DNAI1 was less evident. This substitution was not found in the SNP database and in the analyzed control group, but comparison of the 3'UTR region in ten different species indicated low conservation of the sequence position in question. The variant was therefore analyzed in the context of sequence conservation in this region among different protein coding genes. The 3' regulatory regions are rich in regulatory elements important for the process of mRNA 3'end maturation. Although the sequence conservation and length of these motifs is not very high, some common features have been described [28]. The most important is the highly conserved polyadenylation signal, AAUAAA, a part of UCPAS (upstream core polyadenylation signal). Downstream from it is the cutting site (CS), where pre-mRNA is cut and the polyadenyl tail added; it is often preceded by a CA dinucleotide. The CS distance (10-30 bp) from two flanking segments, UCPAS and the U/GU-rich downstream core polyadenylation signal (DCPAS), is the most conserved feature of this part of the 3' regulatory region. The $\mathrm{G}>\mathrm{A}$

\section{Exon 13}

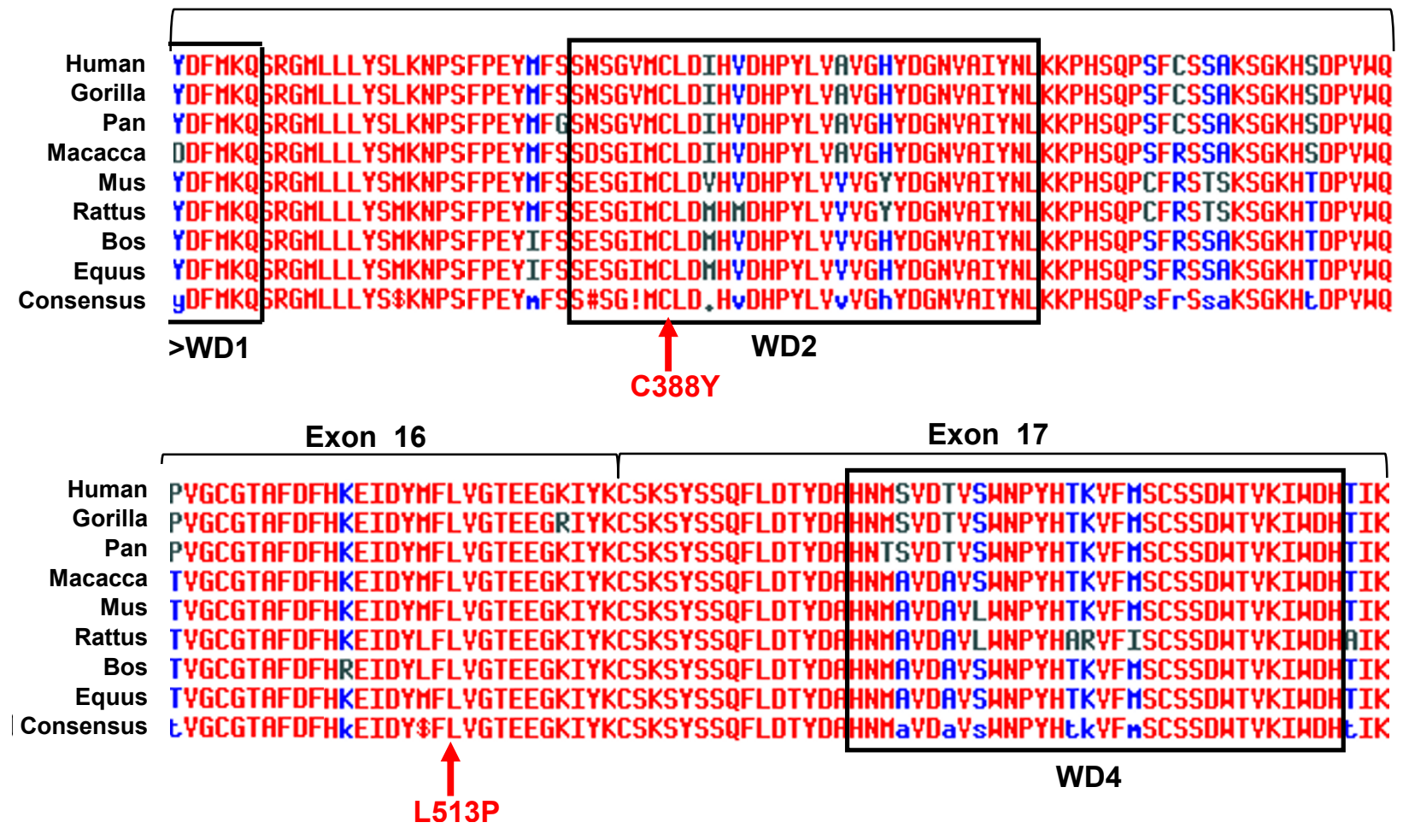

Figure 2 Evolutionary conservation of the sites of two missense mutations. The positions of two missense mutations (arrows) with respect to the position of WD-blocks 2 and 4 (boxed) in exons 13 and 16-17; species comparison indicates high evolutionary conservation. 


\section{...TGA(200bp)TGCACAAAUAAACCUGUGUAGAAACCCACCCCACACCUUUAAUU(G>A)UGCUACCACAGGGCCCU... Stop polyA signal \\ codon \\ (a part of UCPAS) \\ UUGU \\ cutting site \\ (a part of DCPAS)}

Figure 3 Substitution in the DNAI1 3'UTR region. The position of the substitution is highlighted; putative regulatory motifs in the DNA/1 3'UTR region are underlined.

transition found in the patient was located 32 bp downstream from the first fully conserved AAUAAA sequence after the stop codon, and within the UUGU sequence that could be a part of the DCPAS, suggesting its possible effect on mRNA polyadenylation (Figure 3). However, given the generally poor conservation of the regulatory elements among 3'UTR gene sequences, proving the importance of this mutation cannot be assessed without expression analyses. In addition, no sequence change on the complementary allele was found. The patient with the 3'UTR mutation was therefore not included in the analysis of DNAI mutation prevalence among PCD families.

\section{MLPA analysis}

Direct sequencing of the whole coding sequence (exons, splice sites and UTRs), performed in two unrelated patients with monoallelic mutation (IVS1+2-3insT), did not reveal any additional sequence change. The presence of large deletions, not detectable by SSCP and/or sequencing, could explain the failure to detect the second mutated allele. To examine whether this was the case, a multiplex ligation-dependent probe amplification (MLPA) analysis of all the DNAII exons was performed in a subset of $\sim 80$ unrelated patients, including two with the monoallelic mutation and fifteen with the homozygous whole-length SNP-haplotype. The differences in the peaks' height between the samples and the control DNA from healthy individuals did not exceed $20 \%$ (not shown), indicating that no exonic deletion was present in any of the examined patients.

\section{Prevalence of DNAI1 mutations among Polish PCD families}

The disease-associated changes in the DNAI1 sequence were found on 22 non-related chromosomes from twelve families (including two with the monoallelic mutation), which accounts for $8 \%$ of the analyzed cohort of 157 PCD families. Interestingly, when CDO and KS families were considered separately, the proportion of those with DNAI mutations was 5\% (4/83) for CDO and $10 \%$ (8/74) for KS. Due to the small numbers, this difference was not statistically significant (Fisher exact test [SISA], $p \sim 0.09$ ); however, when the proportion of the affected chromosomes (rather than families) harboring DNAI1 mutation was compared, the difference between KS and CDO was statistically significant ( $p \sim 0.008)$.

The prevalence of the IVS1+2-3insT mutation among the 22 mutated chromosomes was $50 \%$, and that of A538T was $36 \%$. To examine the possibility of founder effect(s) being responsible for their distribution in Polish population, DNAI1 mutations were analyzed in context of SNP haplotype background.

\section{SNP haplotype background}

Variants of the 7-position SNP haplotype (flanked by markers located in exon 1 and intron 18 of the DNAI1 gene) were determined in 142 families, including 32 for which linkage of the disease phenotype with DNAI1 was excluded (all chromosomes from these 32 families were considered non-affected). Among the 142 families, 56 had both parents and one (15 families) or more (41 families) children genotyped, in 22 no genotype data was available for one or both parents, and in 64 only a singleton patient was genotyped. Converting the genotype data into haplotypes was aided by the fact that in almost half families (66 families, including 41 singleton patients) at least one of the members was homozygous or heterozygous only at a single SNP position, i.e., haplotype phase could be solved directly. Of the 142, 78 families were informative with respect to the parental contribution of the chromosomes. In the remaining families and in the multiply heterozygous singleton patients, determination of the alleles' phase from genotype data was based on the maximum parsimony principle, taking into account the frequency of the unambiguously determined haplotypes and assuming no recombination whenever possible. In three of the families, the unambiguous solution couldn't be achieved and these were excluded from further haplotype analysis.

The resulting distribution of the haplotypes among 395 non-related chromosomes (183 non-affected and 212 affected) is given in Figure 4. Sixteen haplotype variants were distinguished. Their frequency did not differ significantly when the affected and non-affected chromosomes were compared. Eight of the haplotypes occurred at relatively high frequencies (4-21\%) in the whole analyzed group of 395 chromosomes; the allelic structure of nine rare haplotypes (frequency $\leq 1 \%$ ) suggested that they represented recent recombinants of the frequent variants. Only one of these recombination 


\begin{tabular}{|c|c|c|c|c|c|c|c|c|c|c|c|c|c|c|}
\hline $\begin{array}{l}\text { SNP or } \\
\text { mutation }\end{array}$ & SNP1 & Splice & SNP2 & SNP3 & SNP4 & SNP5 & C388Y & SNP6 & $\begin{array}{l}\text { L513P } \\
\text { G515S }\end{array}$ & A538T & SNP7 & \multicolumn{3}{|c|}{ Number of chromosomes } \\
\hline Location & Ex.1 & Int.1 & Int.1 & Int.4 & Int.8 & Ex.11 & Ex.13 & Int.15 & Ex.16 & Ex.17 & Int.18 & \multirow{2}{*}{$\begin{array}{l}\text { Non- } \\
\text { affected }\end{array}$} & \multicolumn{2}{|c|}{ Affected } \\
\hline $\begin{array}{c}\text { Ancestral } \\
\text { Derived }\end{array}$ & $\begin{array}{l}\mathrm{G} \\
\mathrm{T}\end{array}$ & $\begin{array}{l}\text { Wild } \\
\text { Mut. }\end{array}$ & $\begin{array}{l}\mathrm{g} \\
\mathrm{c} \\
\end{array}$ & $\begin{array}{l}\mathrm{g} \\
\mathrm{a} \\
\end{array}$ & $\begin{array}{l}\mathrm{t} \\
\mathrm{c}\end{array}$ & $\begin{array}{l}G \\
A^{*}\end{array}$ & $\begin{array}{l}\text { Wild } \\
\text { Mut. }\end{array}$ & $\begin{array}{l}\mathrm{a} \\
\mathrm{g}\end{array}$ & $\begin{array}{l}\text { Wild } \\
\text { Mut. }\end{array}$ & $\begin{array}{l}\text { Wild } \\
\text { Mut." }\end{array}$ & $\begin{array}{l}\mathrm{g} \\
\mathrm{c}\end{array}$ & & $\begin{array}{c}\text { No } \\
\text { mutation }\end{array}$ & $\begin{array}{c}\text { With } \\
\text { mutation }\end{array}$ \\
\hline $\mathrm{H} 1$ & 0 & 0 & 0 & 0 & 0 & 0 & 0 & 1 & 0 & $1612 G>A$ & 0 & 10 & 7 & $7^{\dagger}$ \\
\hline $\mathrm{H} 1 \mathrm{r}$ & 0 & 0 & 0 & 0 & 0 & 0 & 0 & 0 & 0 & 0 & 0 & 2 & 0 & \\
\hline $\mathrm{H} 2$ & 0 & $+2-3$ ins $T$ & 0 & 0 & 0 & 0 & 0 & 1 & 0 & 0 & 1 & 20 & 19 & 11 \\
\hline $\mathrm{H} 3$ & 1 & 0 & 0 & 0 & 0 & 0 & 0 & 0 & 0 & 0 & 0 & 10 & 14 & \\
\hline $\mathrm{H} 4$ & 0 & 0 & 0 & 1 & 0 & 0 & 0 & 0 & 0 & 0 & 0 & 20 & 24 & \\
\hline $\mathrm{H} 4 \mathrm{r}$ & 0 & 0 & 0 & 1 & 0 & 0 & 0 & 1 & 0 & 0 & 0 & 0 & 2 & \\
\hline $\mathrm{H} 5$ & 0 & 0 & 0 & 0 & 0 & 1 & 0 & 0 & 0 & 0 & 1 & 30 & 25 & \\
\hline $\mathrm{H} 5 \mathrm{r} 1$ & 0 & 0 & 0 & 0 & 0 & 1 & 0 & 0 & 0 & 0 & 0 & 1 & 3 & \\
\hline $\mathrm{H} 5 \mathrm{r}^{\ddagger}$ & 0 & 0 & 1 & 0 & 1 & 1 & 0 & 0 & 0 & 0 & 1 & 1 & 0 & \\
\hline H5r1r3 & 0 & 0 & 1 & 0 & 0 & 1 & 0 & 0 & 0 & 0 & 0 & 1 & 0 & \\
\hline $\mathrm{H} 6$ & 0 & 0 & 0 & 0 & 0 & 1 & 0 & 0 & 0 & 0 & $0-1^{\S}$ & 9 & 6 & $2^{* *}$ \\
\hline $\mathrm{H} 7$ & 0 & 0 & 1 & 0 & 0 & 0 & $1163 G>A$ & 1 & $1538 \mathrm{~T}>\mathrm{C}$ & 0 & 0 & 36 & 46 & $1+1$ \\
\hline $\mathrm{H} 7 \mathrm{r}$ & 0 & 0 & 1 & 0 & 0 & 0 & 0 & 1 & 0 & 0 & 1 & 1 & 0 & \\
\hline H8 & 0 & 0 & 1 & 0 & 1 & 0 & 0 & 1 & $1543 G>A$ & 0 & 0 & 37 & 40 & 1 \\
\hline H8r1 & 0 & 0 & 1 & 0 & 1 & 0 & 0 & 1 & 0 & 0 & 1 & 2 & 2 & \\
\hline H8r2 & 0 & 0 & 0 & 0 & 1 & 0 & 0 & 1 & 0 & $1612 G>A$ & 0 & 3 & 0 & $1^{\dagger}$ \\
\hline $\begin{array}{l}\text { Figure } \mathbf{4} \mathbf{D} \\
\text { are indicate } \\
2,3,4,5,6 \\
\text { left section } \\
\text { human-chin } \\
\text { haplotype } n \\
\text { into accoun } \\
\text { with the res } \\
\text { background } \\
1 " \text { at the las } \\
\text { rs11999046. }\end{array}$ & $\begin{array}{l}n \text { on th } \\
d 7 \text { der } \\
\text { this Fic } \\
\text { anzee } \\
\text { ne) in t } \\
\text { he exte } \\
\text { ctive } h \\
\text { as four } \\
\text { Dosition } \\
\text { Unknor }\end{array}$ & $\begin{array}{l}\text { n of the } \\
\text { e SNP ha } \\
\text { ote, resp } \\
\text { ure indic } \\
\text { ompariso } \\
\text { he rare ha } \\
\text { ht of LD } \\
\text { plotype } \\
\text { d only in } \\
\text { of the H } \\
\text { in mutati }\end{array}$ & $\begin{array}{l}\text { ilotype } \\
\text { ectively, r } \\
\text { ate, respe } \\
\text { n, with th } \\
\text { aplotype } \\
\text { in the ge } \\
\text { variants. " } \\
\text { KS famili } \\
6 \text { haploty } \\
\text { on(s) in t }\end{array}$ & $\begin{array}{l}\text { n SNP h } \\
\text { packgroun } \\
\text { s1154703, } \\
\text { ctively, th } \\
\text { e sequen } \\
\text { Jariants, } P \\
\text { he region } \\
\text { G > A at } \\
\text { es; A538T } \\
\text { pe denot } \\
\text { wo PCD f }\end{array}$ & $\begin{array}{l}\text { plotype } \\
\text { d. H1 thr } \\
\text { s, rs48797 } \\
\text { e ancestr } \\
\text { ce identi } \\
\text { roposed } \\
\text { (Figure } \\
\text { rs117931 } \\
\text { on the } \\
\text { es ancest } \\
\text { amilies. }\end{array}$ & $\begin{array}{l}\text { variant } \\
\text { ough He } \\
92, \text { rs } 22 \\
\text { al and d } \\
\text { ty indica } \\
\text { assumin } \\
5) \text {, are hi } \\
96 \text { and } \\
-48 \text { r2 was } \\
\text { ral allele }\end{array}$ & $\begin{array}{l}\text { among } \\
\text { r2 are ark } \\
4591, \text { rs3 } \\
\text { arived alle } \\
\text { ing the a } \\
\text { most pa } \\
\text { ghlighted. } \\
1612 \text { are } \\
\text { found in } \\
\text { (G) at rs } 1\end{array}$ & $\begin{array}{l}\text { the stud } \\
\text { itrary nan } \\
\text { '93472, rs } \\
\text { e of the } \\
\text { ncestral s } \\
\text { simoniou } \\
\text { Right sed } \\
\text { transition } \\
\text { a CDO fa } \\
999046,\end{array}$ & $\begin{array}{l}\text { ied chro } \\
\text { nes of the } \\
11793196 \\
\text { SNPs (the } \\
\text { ate). Mini } \\
\text { Is recomb } \\
\text { tion of th } \\
\text { s at CpG } \\
\text { mily. "Rec } \\
\text { inked wit }\end{array}$ & $\begin{array}{l}\text { nosomes } \\
\text { variants } \\
\text {, rs96576. } \\
\text { ancestra } \\
\text { mal regio } \\
\text { ination a } \\
\text { e Figure } \\
\text { dinucleot } \\
\text { ombinati } \\
h \text { the der }\end{array}$ & $\begin{array}{l}\text { 5. Position } \\
\text { of the } 7- \\
20, \text { rs } 1199 \\
\text { I alleles v } \\
\text { ns of rec } \\
\text { mong th } \\
\text { indicates } \\
\text { ides. }{ }^{+} \mathrm{Mu} \\
\text { on detec } \\
\text { ived allel }\end{array}$ & $\begin{array}{l}\text { of the patt } \\
\text { osition SNP } \\
046 \text {. Letters } \\
\text { re determir } \\
\text { mbination } \\
\text { frequent va } \\
\text { he number } \\
\text { tion A538T } \\
\text { d within th } \\
\text { (A) } 93 \text { nt d }\end{array}$ & $\begin{array}{l}\text { hogenic } \mathrm{m} \\
\text { haplotyp } \\
\text { "O" and " } \\
\text { ed from } \\
\text { (letter " } r \text { " in } \\
\text { ariants, anc } \\
\text { of chrom } \\
\text { on the H } \\
\text { e PCD fan } \\
\text { ownstrean }\end{array}$ & $\begin{array}{l}\text { hutations } \\
\text { e. SNP1, } \\
1 \text { " in the } \\
\text { the } \\
\text { n the } \\
\text { d taking } \\
\text { osomes } \\
1 \\
\text { nily. }{ }^{\text {" }} 0- \\
\text { n from }\end{array}$ \\
\hline
\end{tabular}

events was detected within the analyzed families; the remaining eight recombinants must have already "circulated" in the population.

The most prevalent IVS1+2-3insT mutation (found on eleven independent Polish chromosomes), was always found on the G-g-g-t-G-g-c haplotype (lower-case letters indicate SNPs in introns). This common background is consistent with the mutation's identity by descent (i.b.d.) in all the analyzed chromosomes. Another recurring mutation, A538T, was associated with the G-g-g-t-G-g-g haplotype on seven of the eight independent chromosomes, again indicating their recent common origin. Two chromosomes carrying unidentified mutations (in two unrelated patients with the monoallelic IVS1+2-3insT) had an identical haplotype G-g-g-t-A-a-g ( $\mathrm{g}^{\mathrm{a}}$ at the last position of the haplotype denotes ancestral "g" at rs11999046 linked with the derived "a" 93 nt downstream from rs11999046). The identity of the haplotypes background suggests that both families may share the same unidentified complementary mutation.

On the other hand, the background haplotypes for IVS1+2-3insT, A538T and the unknown mutation(s) are relatively frequent also among the non-affected chromosomes (10.9\%, 5.5\% and 4.9\%, respectively). Therefore, the possibility that recurrent mutation events rather than i.b.d. are responsible for the relatively high frequency of these mutations cannot be excluded. In this context it has to be noted that the $1612 \mathrm{G}>\mathrm{A}$ mutation on one of the eight chromosomes was associated with a different haplotype, G-g-g-c-G-g-g. The structure of the G-g-g-c-G-g-g cannot be explained by a single recombination event between two frequent haplotypes (Figure 4), and possible explanations include: 1) a double recombination or a gene conversion involving the frequent haplotype carrying the founder mutation (or its recombination with a very rare variant); 2) the possibility that the less common haplotype is derived from the common haplotype by a mutation at rs3793472; or 3) an independent mutation, which had occurred on a rare haplotype background. The first scenario would suggest the older age of the mutation, since the probability of a recombination or conversion event increases with time (e.g. [29]). Assuming the genomic average of 44 recombinations per meiosis per generation [30], the average genomic crossover rate is $10^{-8}$ per bp per generation, 
and $6 \times 10^{-5}$ per $6 \mathrm{~kb}$ of the DNAI1 haplotype. One could therefore expect a single recombination event to occur once in $10^{4}$ generations or once in $\sim 200,000$ years, and the probability of double recombination event is even lower. Moreover, the DNAI region flanked by markers rs11547036 (in exon 1) and rs11793196 (in exon 11), where at least one of the purported recombination events would have to take place, is characterized by the high level of linkage disequilibrium (Figure 5) in the HapMapCEU sample (http://hapmap.ncbi.nlm.nih.gov; [31,32]). The second scenario, of the recurrent mutation at rs3793472, would point to the identity of $1612 \mathrm{G}>\mathrm{A}$ mutation in both haplotypes (G-g-g-t-G-g-g and G-g-g-c-G-g-g). However, since identical background haplotypes were also found on the unrelated healthy chromosomes (Figure 4), the $\mathrm{t}>\mathrm{c}$ substitution at rs3793472 would have had to occur independently on the chromosomes with and without A538T mutation. With the average mutation rate of $1-4 \times 10^{-8}$ per bp per generation $[33,34]$, this is not highly probable. Regarding the fact that the $1612 \mathrm{G}>$ A transition leading to A538T occurred within a CpG dinucleotide, known to mutate 10 times faster than other sequence positions [35], the third scenario, of an independent recurrent origin of this mutation, appears therefore most plausible.

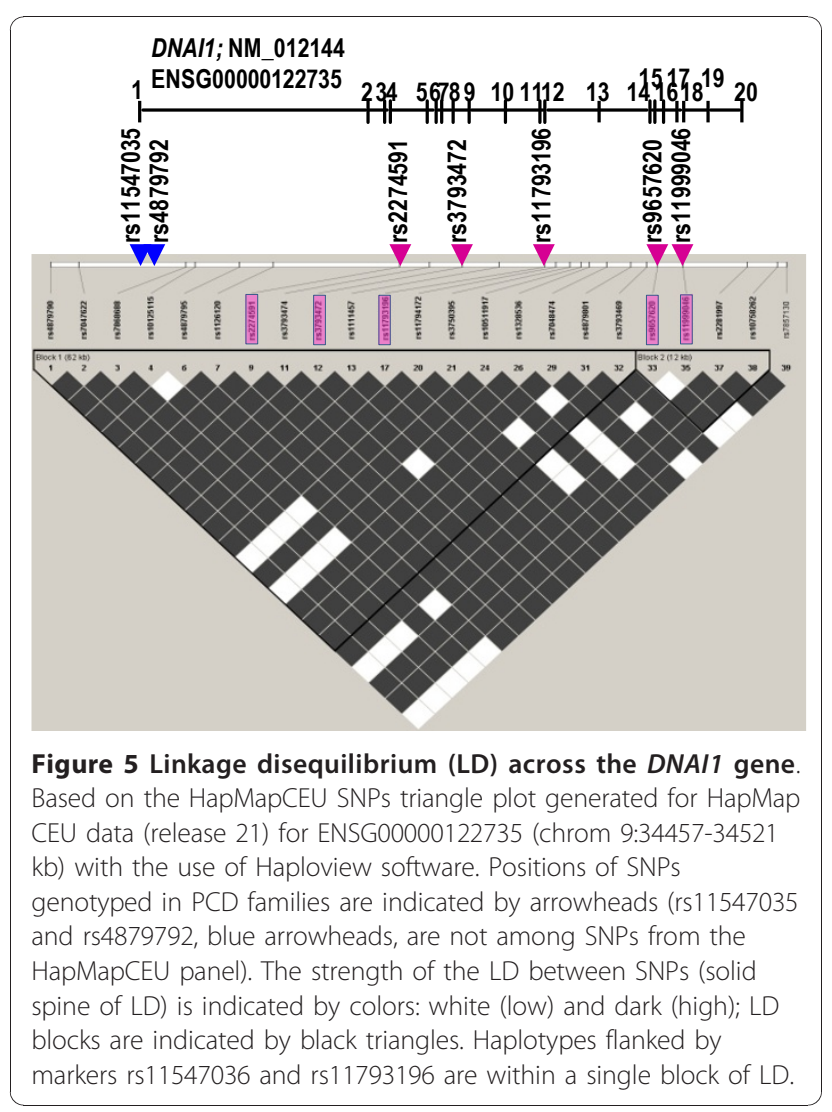

\section{Discussion}

Prevalence of DNAI1 mutations among PCD families of various ethnicities

The disease-associated DNAI mutations were found in $8 \%$ of the analyzed Polish PCD families (12/157). This estimate is consistent with the previously reported DNAI involvement in 9\% of PCD families (16/179) [18]; the earlier, even higher, reported values were based on much smaller study groups $[13,16]$. On the other hand, DNAI1 mutations were found in only $4 \%$ of the 104 PCD families analyzed in another study [20]. The authors suggested that the previously reported involvement of DNAI1 mutations reflected bias in the recruitment of PCD patients through detection of ODA defects. Indeed, the frequency of DNAI1 mutations in the pre-selected PCD subpopulation with documented ODA defects has been shown to be higher (14\%) $[2,18]$. However, our estimate of $8 \%$ is based on the total number of Polish families, recruited without any preselection. Similarly, the criticized estimate of $9 \%$ [18] has been calculated with respect to all the $179 \mathrm{PCD}$ families recruited for that study; even if the proportion of families with ODA defects in that cohort was shown to be $\sim 80 \%$, it did not necessarily reflect biased recruitment but rather the frequent presence of ODA defects among PCD patients in general. Therefore, the lowest reported involvement of DNAI1 [20] may reflect other factors, for example ethnic differences in the analyzed cohorts.

Of the 104 families analyzed by Failly et al. [20], 101 were Caucasian, with the predominant (3/4) contribution of Swiss $(n=50)$ or Italian $(n=32)$. The cohort analyzed by Zariwala et al. [18] was ethnically more heterogeneous: 155 of 179 families were Caucasian, and among 90 families for whom the ethnicity data were provided, the majority were German $(n=28)$, French $(n=23)$, UK $(n=18)$ and Australian $(n=11)$; only 6 samples were Italian, and no Swiss samples were reported. Our study group $(n=157)$ was predominantly Polish $(n=151)$; six families of Chech/Slovakian origin belong to the populations which are geographically and ethnically very close to Poles (all belong to West Slavs). Our results indicate that Poles (West Slavs), do not significantly differ from German, French or British populations when the DNAI1 involvement in PCD pathogenesis is considered $[13,16,18]$. The low prevalence of DNAI1 mutations among patients of Italian and Swiss origin [20] may either reflect specificity of these two populations or result from a clinal distribution of DNAI1 mutations, with the frequency gradient running in South-North rather than West-East direction. The existence of such gradients in Europe can be exemplified by the frequency distribution of the F508del mutation in the CFTR gene [36]. Answering the question whether 
the differences in DNAI1 involvement is due to the possible European clines in the geographical distribution of mutations or to the local founder effects will require studying PCD patients from other European populations.

\section{Population spectrum of DNAl1 mutations}

The spectrum of DNAI1 mutations detected up to date in all the relevant studies is shown in Table 3 . The prevalence of IVS1+2-3insT among the Polish PCD chromosomes harboring DNAI1 mutations $(50 \%, 11 / 22)$ is only slightly lower than the respective value based on all the previous reports $(56 \%, 27 / 48)[13,15,18,20]$. The common background of this mutation in all the Polish chromosomes is consistent with their identity by descent. The origin of the recurring IVS1+2-3insT from the common founder has been suggested in earlier studies based on sharing allele 19CA of the nearby microsatellite D9S1805, located $0.26 \mathrm{Mb}$ upstream of DNAI1 [18].

The relatively high prevalence of A538T (36\%, 8/22) appears to be specific for the Polish population; in all the other studies combined, this mutation represented only $1 \%(2 / 48)$ of DNAI mutations. Polish cohort is the only population where PCD patients homozygous for other alleles than IVS1+2-3T were found: three families without reported consanguinity were homozygous for A538T. The high frequency of A583T among Polish patients most likely reflects two phenomena: the common origin (founder mutation) in most families, and an independent mutation event on a different haplotype background in another family. Further studies involving other Eastern-European PCD cohort/s would be

Table 3 The distribution of mutations reported up to date in the KS and CDO families

\begin{tabular}{|c|c|c|c|c|c|c|c|c|c|c|c|c|c|c|c|c|}
\hline \multicolumn{3}{|c|}{ Study } & \multicolumn{2}{|c|}{ Pennarun99 } & \multicolumn{2}{|c|}{ Guichard01 } & \multicolumn{2}{|c|}{ Zariwala01 } & \multicolumn{2}{|c|}{ Zariwala06 } & \multicolumn{2}{|c|}{ Failly08 } & \multicolumn{2}{|c|}{$\begin{array}{l}\text { This } \\
\text { study }\end{array}$} & \multicolumn{2}{|c|}{ All } \\
\hline KS & CDO & KS & CDO & KS & CDO & KS & CDO & KS & CDO & KS & CDO & KS & CDO & & & \\
\hline \multicolumn{17}{|c|}{ Families $(n=487)$} \\
\hline \multicolumn{3}{|c|}{ Cohort size (\# families) } & 2 & 4 & 34 & - & 5 & 2 & 93 & 86 & 61 & 43 & 74 & 83 & 269 & 218 \\
\hline \multicolumn{2}{|c|}{$\begin{array}{c}\text { Families with mutations } \\
\text { detected } \\
\text { (\% of all studied PCD families) }\end{array}$} & 2 mutations & & 1 & 3 & & 1 & 1 & 7 & 7 & 1 & 1 & 8 & 2 & $\begin{array}{c}21 \\
(8 \%)\end{array}$ & $\begin{array}{c}17 \\
(8 \%)\end{array}$ \\
\hline 1 mutation & & & & & & & 1 & 1 & & 2 & & 2 & & & & \\
\hline Exon/Intron & Mutation & Effect & \multicolumn{14}{|c|}{ Chromosomes with mutations $(n=70)$} \\
\hline $\ln 1$ & IVS1+2-3insT & $\mathrm{S} 17 \mathrm{fs} \times 25$ & & 1 & 3 & & 1 & 1 & 10 & 7 & 2 & 2 & 6 & 5 & 22 & 16 \\
\hline Ex5 & 282-283 insAATA & G95N fsX24 & & 1 & & & & & & & & & & & & 1 \\
\hline Ex6 & 463delA & T155LfSX18 & & & & & & & & 1 & & & & & & 1 \\
\hline Ex7 & $520 G>A$ & E174L & & & & & & & & & & 1 & & & & 1 \\
\hline $\ln 7$ & IVS7-2A > G & splicingAcc & & & & & & & 1 & & & & & & 1 & \\
\hline Ex10 & $874 \mathrm{C}>\mathrm{T}$ & Q292X & & & & & & & & 1 & & & & & & 1 \\
\hline $\ln 10$ & IVS10-4-7 delGTTT & splicingAcc & & & & & & & & 1 & & & & & & 1 \\
\hline Ex13 & $1163 G>A$ & C388Y & & & & & & & & & & & 1 & & 1 & \\
\hline$"$ & $1212 T>G$ & Y404X & & & & & & & 1 & & & & & & 1 & \\
\hline$"$ & $1222 G>A$ & V408M & & & & & & & 1 & & & & & & 1 & \\
\hline$"$ & $1307 G>A$ & W436X & & & & & & & & 1 & & & & & & 1 \\
\hline Ex16 & $1490 G>A$ & R468-K523del & & & & & & & & 1 & & & & & & 1 \\
\hline$"$ & $1538 \mathrm{~T}>\mathrm{C}$ & L513P & & & & & & & & & & & 1 & & 1 & \\
\hline$"$ & $1543 G>A$ & G515S & & & 2 & & & & & & & & 1 & & 3 & \\
\hline Ex17 & $1612 G>A$ & A538T & & & & & & & 1 & 1 & & & 7 & 1 & 8 & 2 \\
\hline$"$ & $1644 G>A$ & W548X & & & & & & & 1 & & & & & & 1 & \\
\hline$"$ & 1657-68del & T553-F556del & & & 1 & & & & & & & & & & 1 & \\
\hline$"$ & $1703 G>C$ & W568S & & & & & 1 & & & & & 1 & & & 1 & 1 \\
\hline$"$ & $1704 G>A$ & W568X & & & & & & 1 & & & & & & & & 1 \\
\hline Ex19 & 1926-7insCC & 1643PfsX48 & & & & & & & & 1 & & & & & & 1 \\
\hline $\ln 19$ & IVS19+1G > A & A607-K667del & & & & & & & & 1 & & & & & & 1 \\
\hline & Number of & chromosomes & with $D I$ & $A / 1 \mathrm{~m}$ & utation & $(\%$ & of all $\mathrm{r}$ & $\mathrm{D} \mathrm{ch}$ & romo & mes) & & & & & $41(8 \%)$ & $29(7 \%$ \\
\hline
\end{tabular}


required to elucidate whether the founder mutation is restricted to the Polish population or characteristic for other Slavic groups. The excess of Polish PCD chromosomes harboring A538T was observed among the KS families; in fact, it is this mutation, which mostly contributed to the DNAI1 involvement being higher in KS than in CDO families.

Importantly for diagnostic purposes, A538T is located in exon 17, and two new mutations detected in this study (C388Y and L513P)-in exons 13 and 16, respectively, such that most of the mutant alleles remain clustered in intron 1 and exons 13, 16 and 17, as previously reported $[2,18]$. Chromosomes harboring mutations in these regions make up $80 \%$ of all the PCD chromosomes with the reported DNAII involvement. Of note, while the rare nonsense mutations or changes introducing a frame shift are distributed along the whole coding sequence, all but one (E174L) missense mutations are found in exons 13, 16 and 17.

\section{A question of unidentified DNAI1 mutations}

Among a total of 38 PCD families with the DNAI mutations found in different studies, six were "monoallelic", with only one mutation identified in spite of direct sequencing of the whole coding region $[[18,20]$ this study]. In four of these families, the single mutation found was the frequent IVS1+2-3insT. Is it possible that the affected members in these four families were just carriers of the detected mutation (with DNAI1 not being involved in PCD pathogenesis)? In such a case, the estimate of DNAI1 involvement in PCD pathogenesis would be slightly lower $(7 \%$; 34/487). With the disease prevalence of $1 / 20,000, D N A I 1$ involvement of $\sim 7-10 \%$, and IVS1+2-3insT prevalence among DNAI1 mutations of $\sim 50 \%$, the chance of picking up an asymptomatic IVS1 +2 -3ins T carrier in the general population is $\sim 1 / 535-1 /$ 450. Given that 487 independent PCD families were analyzed in all the reported studies, one would expect at most one of the patients to be an asymptomatic carrier of IVS1+2-3insT; the observed number of four carriers is higher, although the difference does not reach the level of statistical significance ( $p=0.15$; Fisher test). Nevertheless, we tentatively assume that DNAI1 is actually involved in PCD pathogenesis in the families with monoallelic mutation. In that case, the second mutation must have been undetectable by SSCP screening and direct sequencing of the amplified exonic segments. One of the possible explanations- the presence of long exonic deletion - was excluded, since the MLPA analysis using probes targeting all the DNAII exons did not reveal any differences in the amplification intensity of the PCD patients as compared to healthy controls. However, deep intronic or extragenic regulatory mutations remain to be searched for. Finally, the possibility that the inheritance of PCD in some families is di- or trigenic cannot be formally excluded, but so far no evidence exists which could substantiate this hypothesis.

\section{Conclusions}

The analysis of the Polish PCD patients confirms large genetic heterogeneity of the disease and indicates that the worldwide involvement of DNAI1 mutations in PCD pathogenesis ranges from 7 to $10 \%$ in the families not preselected for the ODA defects; however, the involvement in specific populations may differ from this global estimate. In the combined PCD cohorts from all up to date studies, the IVS1+2-3insT remains the most prevalent pathogenetic change in DNAI1 (54\% of all the mutations identified worldwide). The increased global prevalence of A538T (14\%) is due to the contribution of the Polish cohort, in which the high frequency of this mutation (36\%) probably reflects the local (Polish or Slavic) founder effect. The spectrum of mutations detected in the Polish cohort confirms earlier observations of mutations clustering in (or around) exons 1, 13, 16 and 17 of the DNAI1 gene, indicating directions for future diagnostic tests. Finally, with MLPA results indicating that no large exonic DNAI1 deletions are involved in PCD pathogenesis, the question of undetected mutations still remains open.

\section{Abbreviations}

ASO: allele-specific oligonucleotide; CDO: ciliary dysfunction only; IDA: inner dynein arms; KS: Kartagener syndrome; MLPA: multiplex ligation-dependent probe amplification; MT: microtubules; ODA: outer dynein arms; PCD: primary ciliary dyskinesia; s.i.: situs inversus

\section{Acknowledgements and Funding}

We gratefully acknowledge Polish PCD families for contributing blood samples for this study. An informed consent was obtained from all the patients or their parents; the research protocol was approved by the Ethics Committee of the Medical University in Poznan.

The study was supported by grants from the Polish Scientific Committee: KBN-3PO5E-03824 (EZ), PBZ-KBN122/P05-1 (EZ), NN401-277534 (EZ), NN40109-5537 (MW); and by ECFP7 grant HEALTH-PROT-GA No 229676 (MW).

\section{Author details}

${ }^{1}$ Institute of Human Genetics, Poznań, Poland. ${ }^{2}$ Institute of Tuberculosis and Lung Diseases, Rabka, Poland. ${ }^{3}$ International Institute of Molecular and Cell Biology, Warszawa, Poland.

\section{Authors' contributions}

EZ designed and coordinated the study, performed haplotype analysis and interpretation of data, and drafted the manuscript, BN and KV carried the majority of SSCP and MLPA assays and participated in sequence analysis, US, $\mathrm{ZB}, \mathrm{KH}$ and HP participated in SSCP assays and sequence analysis, ER was responsible for assembling, maintaining and monitoring the sample collection, AP recruited PCD families and provided clinical assessment of the patients, MW conceived the study and participated in its design. All authors read and approved the final manuscript.

\section{Competing interests}

The authors declare that they have no competing interests.

Received: 28 September 2010 Accepted: 8 December 2010 Published: 8 December 2010 


\section{References}

1. Afzelius BA, Mossberg B: Immotile-cilia syndrome (primary ciliary dyskinesia), including Kartagener syndrome. The Metabolic and Molecular Bases of Inherited Disease New York: McGraw-Hill, Inc; 1995, 3943-54.

2. Morillas HN, Zariwala M, Knowles MR: Genetic causes of bronchiectasis: primary ciliary dyskinesia. Respiration 2007, 74:252-63.

3. Narayan D, Krishnan SN, Upender M, Ravikumar TS, Mahoney MJ, Dolan TF Jr, Teebi AS, Haddad GG: Unusual inheritance of primary ciliary dyskinesia (Kartagener's syndrome). J Med Genet 1994, 31:493-6.

4. Krawczyński MR, Witt M: PCD and RP: X-linked inheritance of both disorders? Pediatr Pulmonol 2004, 38:88-9.

5. Krawczyński MR, Dmeńska H, Witt M: Apparent X-linked primary ciliary dyskinesia associated with retinitis pigmentosa and a hearing loss. $J$ Appl Genet 2004, 45:107-10.

6. Moore A, Escudier E, Roger G, Tamalet A, Pelosse B, Marlin S, Clement A Geremek M, Delaisi B, Bridoux AM, Coste A, Witt M, Duriez B, Amselem S: RPGR: is mutated in patients with a complex $X$ linked phenotype combining primary ciliary dyskinesia and retinitis pigmentosa. J Med Genet 2006, 43:326-333.

7. Blouin JL, Meeks M, Radhakrishna U, Sainsbury A, Gehring C, Sail GD, Bartoloni L, Dombi V, O'Rawe A, Walne A, Chung E, Afzelius BA, Armengot $M$, Jorissen $M$, Schidlow DV, van Maldergem $L$, Walt $H$, Gardiner RM, Probst D, Guerne PA, Delozier-Blanchet CD, Antonarakis SE: Primary ciliary dyskinesia: a genomewide linkage analysis reveals extensive locus heterogeneity. Eur J Hum Genet 2000, 8:109-118.

8. Meeks M, Walne A, Spiden S, Simpson H, Mussaffi-Georgy H, Hamam HD, Fehaid EL, Cheehab M, Al-Dabbagh M, Polak-Charcon S, Blau H, O'Rawe A, Mitchison HM, Gardiner RM, Chung E: A locus for primary ciliary dyskinesia maps to chromosome 19q. J Med Genet 2000, 37:241-244.

9. Jeganathan D, Chodhari R, Meeks M, Faeroe O, Smyth D, Nielsen K, Amirav I, Luder AS, Bisgaard H, Gardiner RM, Chung EM, Mitchison HM: Loci for primary ciliary dyskinesia map to chromosome 16p12.1-12.2 and 15q13.1-15.1 in Faroe Islands and Israeli Druze genetic isolates. J Med Genet 2004, 41:233-40.

10. Geremek M, Zietkiewicz E, DiehI SR, Alizadeh BZ, Wijmenga C, Witt M: Linkage analysis localises a Kartagener syndrome gene to a $3.5 \mathrm{cM}$ region on chromosome 15q24-25. J Med Genet 2006, 43:1-6.

11. Geremek $M$, Witt M, Primary ciliary dyskinesia: genes, candidate genes and chromosomal regions. J Appl Genet 2004, 45:347-61.

12. Escudier E, Duquesnoy P, Papon JF, Amselem S: Ciliary defects and genetics of primary ciliary dyskinesia. Paediatr Respir Rev 2009, 10:51-4.

13. Pennarun G, Escudier E, Chapelin C, Bridoux AM, Cacheux V, Roger G, Clement A, Goossens M, Amselem S, Duriez B: Loss-of-function mutations in a human gene related to Chlamydomonas reinhardtii dynein IC78 result in primary ciliary dyskinesia. Am J Hum Genet 1999, 65:1508-1519.

14. Omran H, Häffner K, Völkel A, Kuehr J, Ketelsen UP, Ross UH, Konietzko N, Wienker T, Brandis M, Hildebrandt F: Homozygosity mapping of a gene locus for primary ciliary dyskinesia on chromosome $5 \mathrm{p}$ and identification of the heavy dynein chain DNAH5 as a candidate gene. Am J Respir Cell Mol Biol 2000, 23:696-702.

15. Guichard C, Harricane MC, Lafitte JJ, Godard P, Zaegel M, Tack V, Lalau G, Bouvagnet P: Axonemal dynein intermediate-chain gene (dnai1) mutations result in situs inversus and primary ciliary dyskinesia (Kartagener syndrome). Am J Hum Genet 2001, 68:1030-1035.

16. Zariwala M, Noone PG, Sannuti A, Minnix S, Zhou Z, Leigh MW, Hazucha M, Carson $J$, Knowles MR: Germline mutations in an intermediate chain dynein cause primary ciliary dyskinesia. Am J Respir Cell Mol Biol 2001, 25:577-583.

17. Olbrich H, Haffner K, Kispert A, Volkel A, Volz A, Sasmaz G, Reinhardt R, Hennig S, Lehrach $\mathrm{H}$, Konietzko N, Zariwala M, Noone PG, Knowles M, Mitchison HM, Meeks M, Chung EM, Hildebrandt F, Sudbrak R, Omran H: Mutations in DNAH5 cause primary ciliary dyskinesia and randomization of left-right asymmetry. Nat Genet 2002, 30:143-144.

18. Zariwala MA, Leigh MW, Ceppa F, Kennedy MP, Noone PG, Carson JL, Hazucha MJ, Lori A, Horvath J, Olbrich H, Loges NT, Bridoux AM, Pennarun G, Duriez B, Escudier E, Mitchison HM, Chodhari R, Chung EM, Morgan LC, de longh RU, Rutland J, Pradal U, Omran H, Amselem S, Knowles MR: Mutations of DNA/1 in primary ciliary dyskinesia: evidence of founder effect in a common mutation. Am J Respir Crit Care Med 2006, 174:858-866
19. Hornef N, Olbrich H, Horvath J, Zariwala MA, Fliegauf M, Loges NT, Wildhaber J, Noone PG, Kennedy M, Antonarakis SE, Blouin JL, Bartoloni L, Nusslein $T$, Ahrens $P$, Griese $M$, Kuhl $H$, Sudbrak R, Knowles MR, Reinhardt $R$, Omran $\mathrm{H}$ : DNAH5 mutations are a common cause of primary ciliary dyskinesia with outer dynein arm defects. Am J Respir Crit Care Med 2006, 174:120-126.

20. Failly M, Saitta A, Muñoz A, Falconnet E, Rossier C, Santamaria F, de Santi MM, Lazor R, DeLozier-Blanchet CD, Bartoloni L, Blouin JL: DNA/1 mutations explain only $2 \%$ of primary ciliary dykinesia. Respiration 2008 , 76:198-204.

21. Failly M, Bartoloni L, Letourneau A, Munoz A, Falconnet E, Rossier C, de Santi MM, Santamaria F, Sacco O, DeLozier-Blanchet CD, Lazor R, Blouin JL: Mutations in DNAH5 account for only $15 \%$ of a non-preselected cohort of patients with primary ciliary dyskinesia. J Med Genet 2009, 46:281-6.

22. Omran H, Kobayashi D, Olbrich H, Tsukahara T, Loges NT, Hagiwara H, Zhang Q, Leblond G, et al: Ktu/PF13 is required for cytoplasmic preassembly of axonemal dyneins. Nature 2008, 456:611-617.

23. Castleman VH, Romio L, Chodhari R, Hirst RA, de Castro SC, Parker KA, YbotGonzalez P, Emes RD, Wilson SW, Wallis C, Johnson CA, Herrera RJ, Rutman A, Dixon M, Shoemark A, Bush A, Hogg C, Gardiner RM, Reish O, Greene ND, O'Callaghan C, Purton S, Chung EM, Mitchison HM: Mutations in radial spoke head protein genes $R S P H 9$ and $R S P H 4 A$ cause primary ciliary dyskinesia with central-microtubular-pair abnormalities. Am J Hum Genet 2009, 84:197-209.

24. Loges NT, Olbrich H, Fenske L, Mussaffi H, Horvath J, Fliegauf M, Kuhl H, Baktai G, Peterffy E, Chodhari R, Chung EM, Rutman A, O'Callaghan C, Blau H, Tiszlavicz L, Voelkel K, Witt M, Zietkiewicz E, Neesen J, Reinhardt R, Mitchison HM, Omran $\mathrm{H}$ : DNAI2 mutations cause primary ciliary dyskinesia with defects in the outer dynein arm. Am J Hum Genet 2008, 83:547-58.

25. Loges NT, Olbrich H, Becker-Heck A, Häffner K, Heer A, Reinhard C, Schmidts M, Kispert A, Zariwala MA, Leigh MW, Knowles MR, Zentgraf $H$, Seithe $H$, Nürnberg $G$, Nürnberg $P$, Reinhardt $R$, Omran $H$ : Deletions and point mutations of $\angle R R C 50$ cause primary ciliary dyskinesia due to dynein arm defects. Am J Hum Genet 2009, 85:883-9.

26. Bourgeois S, Labuda D: Dynamic allele-specific oligonucleotide hybridization on solid support. Anal Biochem 2004, 324:309-11.

27. Yue P, Li Z, Moult J: Loss of protein structure stability as a major causative factor in monogenic disease. J Mol Biol 2005, 353:459-73.

28. Chen JM, Férec C, Cooper DN: A systematic analysis of disease-associated variants in the $3^{\prime}$ regulatory regions of human protein-coding genes I: general principles and overview. Hum Genet 2006, 120:1-21.

29. Slatkin M, Rannala B: Estimating allele age. Annu Rev Genomics Hum Genet 2000, 1:225-49.

30. Broman KW, Murray JC, Sheffield VC, White RL, Weber JL: Comprehensive human genetic maps: Individual and sex-specific variation in recombination. Am J Hum Genet 1998, 63:861-869.

31. The International HapMap Consortium: The international HapMap project. Nature 2003, 426:789-796

32. The International HapMap Consortium: A haplotype map of the human genome. Nature 2005, 437:1299-1320

33. Bailey WJ, Fitch DH, Tagle DA, Czelusniak J, Slightom JL, Goodman M: Molecular evolution of the psi eta-globin gene locus: gibbon phylogeny and the hominoid slowdown. Mol Biol Evol 1991, 8:155-84

34. Li WH, Sadler LA: Low nucleotide diversity in man. Genetics 1991, 129:513-523.

35. Bird AP: DNA methylation and the frequency of CpG in animal DNA. Nucleic Acids Res 1980, 8:1499-1504.

36. Casals T, Vazquez C, Lázaro C, Girbau E, Gimenez FJ, Estivill X: Cystic fibrosis in the Basque country: high frequency of mutation delta F508 in patients of Basque origin. Am J Hum Genet 1992, 50:404-410.

37. Karadag B, James AJ, Gültekin E, Wilson NM, Bush A: Nasal and lower airway level of nitric oxide in children with primary ciliary dyskinesia. Eur Respir J 1999, 13:1402-5.

38. Noone PG, Leigh MW, Sannuti A, Minnix SL, Carson JL, Hazucha M, Zariwala MA, Knowles MR: Primary ciliary dyskinesia: diagnostic and phenotypic features. Am J Respir Crit Care Med 2004, 15(169):459-67.

doi:10.1186/1465-9921-11-174

Cite this article as: Ziętkiewicz et al:: Population specificity of the DNAl1 gene mutation spectrum in primary ciliary dyskinesia (PCD). Respiratory Research 2010 11:174. 